\title{
Passive and active ventricular elastances of the left ventricle Liang Zhong ${ }^{\dagger}$, Dhanjoo N Ghista*†1,2, Eddie YK Ng1 and Soo T Lim ${ }^{3}$
}

Address: ${ }^{1}$ College of Engineering, School of Mechanical and Production Engineering, Nanyang Technological University, 50 Nanyang Avenue, Singapore 639798, ${ }^{2}$ Bioengineering Division, College of Engineering, Nanyang Technological University, Singapore, 639798 and ${ }^{3}$ Department of Cardiology, National Heart Centre, SingHealth, Mistri Wing, 3rd Hospical Ave., Singapore, 168572

Email: Liang Zhong - pg01538918@ntu.edu.sg; Dhanjoo N Ghista* - mdnghista@ntu.edu.sg; Eddie YK Ng - mykng@ntu.edu.sg; Soo T Lim - LIM_SOO_TEIK@nhc.com.sg

* Corresponding author †Equal contributors

Published: II February 2005

BioMedical Engineering OnLine 2005, 4:10 doi:10.1186/1475-925X-4-10
Received: 06 December 2004

Accepted: II February 2005

This article is available from: http://www.biomedical-engineering-online.com/content/4/I/10

(c) 2005 Zhong et al; licensee BioMed Central Ltd.

This is an Open Access article distributed under the terms of the Creative Commons Attribution License (http://creativecommons.org/licenses/by/2.0), which permits unrestricted use, distribution, and reproduction in any medium, provided the original work is properly cited.

\begin{abstract}
Background: Description of the heart as a pump has been dominated by models based on elastance and compliance. Here, we are presenting a somewhat new concept of time-varying passive and active elastance. The mathematical basis of time-varying elastance of the ventricle is presented. We have defined elastance in terms of the relationship between ventricular pressure and volume, as: $d P=E d V+V d E$, where $E$ includes passive $\left(E_{p}\right)$ and active $\left(E_{a}\right)$ elastance. By incorporating this concept in left ventricular (LV) models to simulate filling and systolic phases, we have obtained the time-varying expression for $E_{a}$ and the $L V$-volume dependent expression for $E_{p}$.

Methods and Results: Using the patient's catheterization-ventriculogram data, the values of passive and active elastance are computed. $E_{a}$ is expressed as: $E_{a}=E_{a 0}\left(1-e^{-\left(\frac{t}{\tau_{C}}\right)^{Z_{c}}}\right)\left(e^{-\left(\frac{t-d}{\tau_{R}}\right)^{Z_{R}}}\right) ; E_{\mathrm{p}}$ is represented as: $E_{p}=E_{p 0} e^{z_{p} V} . E_{\mathrm{a}}$ is deemed to represent a measure of LV contractility. Hence, Peak dP/dt and ejection fraction (EF) are computed from the monitored data and used as the traditional measures of LV contractility. When our computed peak active elastance $\left(\mathrm{E}_{\mathrm{a}, \max }\right)$ is compared against these traditional indices by linear regression, a high degree of correlation is obtained. As regards $E_{p}$, it constitutes a volumedependent stiffness property of the LV, and is deemed to represent resistance-to-filling.

Conclusions: Passive and active ventricular elastance formulae can be evaluated from a single-beat P-V data by means of a simple-to-apply LV model. The active elastance $\left(E_{a}\right)$ can be used to characterize the ventricle's contractile state, while passive elastance $\left(E_{p}\right)$ can represent a measure of resistance-to-filling.
\end{abstract}

\section{Background}

The heart may be conceived as a pump that receives blood from a low-pressure system and raises it to a high-pressure system. Although the mechanism responsible for generation of wall stress (and hence left ventricular (LV) pres- sure) is contraction of the myocardial fibers, an analytical formulation linking the myocardial and LV dynamics is still lacking. In the absence of this formulation, a popular way of linking LV pressure and volume dynamics is by means of LV compliance (or elastance) [1,2]. Although 
this yields the cyclic values of elastance and compliance, this concept does not provide an intrinsic measure of elastance and compliance for the contractile state of the LV.

The concept of compliance or elastance was first employed for blood vessels [3], by relating incremental cross-section area (or volume) and transmural pressure. Warner appears to be have been the first to adopt a compliance description for a dynamic heart [4]. In Warner's description, a mean value of compliance is adopted for diastolic phase and another mean value for systole, with abrupt transitions between the two states.

Defares [5] avoided the stepwise transition between diastolic and systolic compliance, by making elastance a continuously varying function of time. Later, the concept of a continuously varying compliance or elastance was adopted by a number of investigators with diverse variations $[2,6,7]$. Nevertheless, they all share the concept of a simple and extrinsic compliance term as an adequate description of ventricular mechanics during the cardiac cycle, based on monitored values of LV pressure and volume.

Classically, ventricular compliance is defined, at any point in time, as the change in ventricular volume concomitant with the change in ventricular pressure, such that

$C=d V / d P, E=d P / d V$

If $\mathrm{C}$ is assumed constant, this equation becomes a linear relation, whose integration gives

$V=C P+V_{c}$

where $\mathrm{V}_{\mathrm{c}}$ is an integration constant. If the compliance varies with time, then all terms in equation (2) may vary with time, as:

$V(t)-V_{c}(t)=C(t) P(t)$

In this context, Suga [8] opted for the definition of ventricular elastance as

$$
E(t)=\frac{P(t)}{V(t)-V_{d}}
$$

to represent the elastance of the contracting $L V$, where $V_{d}$ represents the unstressed $\mathrm{LV}$ volume corresponding to zero LV-pressure, obtained by drawing a tangent to P-V curves at end-ejection, as illustrated in Figure 1. This model gave rise to the development of the end-systolic pressure-volume relation (ESPVR) as a measure of contractility [9-14].

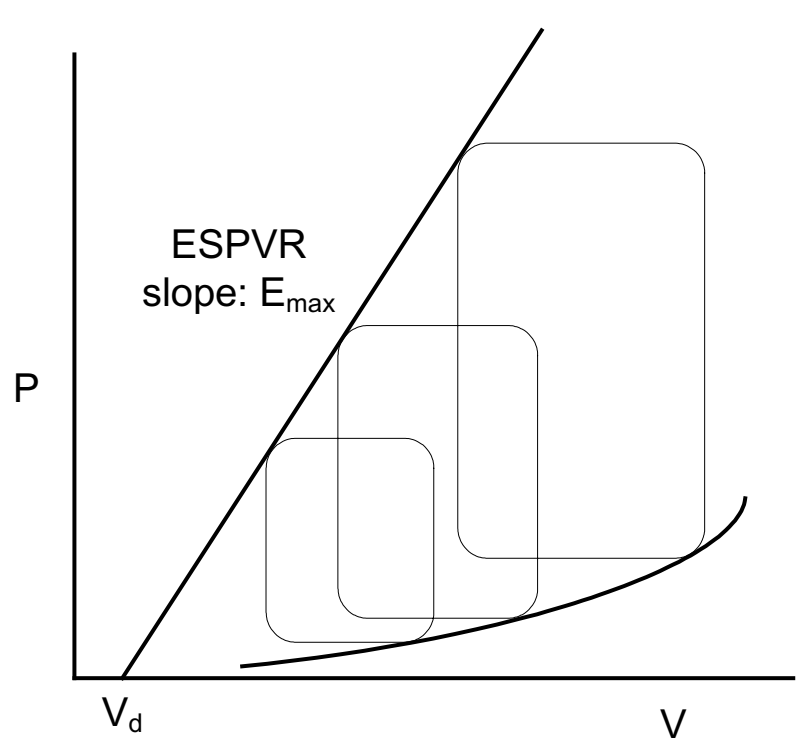

Figure I

Schematic drawing of P-V loops and end-systolic P-V relation (ESPVR). Schematic drawing of P-V loops and end-systolic P-V relationship (ESPVR) with a positive volume intercept $V_{d}$. The slope of ESPVR line is deemed to be $E_{\max }$.

However, the determination of the maximal slope $\mathrm{E}_{\max }$ and of the volume-axis intercept $\left(\mathrm{V}_{\mathrm{d}}\right)$ of the tangent to the $\mathrm{P}-\mathrm{V}$ curve at end-ejection (as a measure contractility of the cardiac muscle) is not only unreliable $[11,15]$, but also requires generation of multiple $\mathrm{P}-\mathrm{V}$ loops under variations loading conditions $[11,15]$. It is hence impractical to use clinically for a specific LV catheterization-ventriculography data. Above all, all of these variations in the concept of $\mathrm{E}$ obtained from LV pressure-volume data fail to explain the phenomena of LV suction and LV pressure drop during early filling as well as the generation of $\mathrm{LV}$ pressure increase during isovolumic contraction.

We have hence come up with a new concept of dual passive and active elastances operating throughout the cardiac cycle. The passive elastance $\left(\mathrm{E}_{\mathrm{p}}\right)$ represents the $\mathrm{LV}$ pressure response to $\mathrm{LV}$ volume change (to $\mathrm{LV}$ volume increase during LV filling phase and to LV volume decrease during LV ejection phase). However, simultaneously, we also have active elastance $\left(\mathrm{E}_{\mathrm{a}}\right)$ representing the contraction of the left ventricle due to its sarcomeric activation (and the development of force between the actinmyosin units) and relaxation (due to disengagement of the actin-myosin units).

$L V E_{a}$ develops after the start of isovolumic contraction, becomes maximum some time during late ejection and 

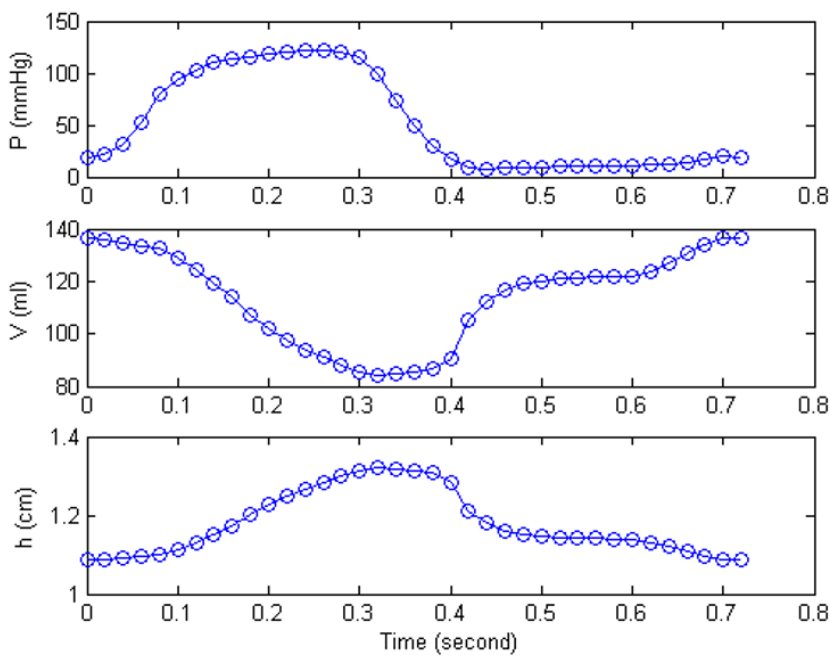

Figure 2

A case study of measured LV pressure, volume and wall thickness during a cardiac cycle. An example of a patient's measured LV pressure, volume and wall thickness during a cardiac cycle; $\mathrm{t}=0-0.08 \mathrm{~s}$ is the isovolumic contraction phase, $\mathrm{t}=0.08 \mathrm{~s}-0.32 \mathrm{~s}$ is the ejection phase, $\mathrm{t}=0.32 \mathrm{~s}$ $0.40 \mathrm{~s}$ is the isovolumic relaxation phase, and $\mathrm{t}=0.40 \mathrm{~s}-0.72 \mathrm{~s}$ is the filling phase. Note that even after $0.4 \mathrm{~s}$, the LV pressure still continues to decrease from $17 \mathrm{mmHg}$ (at $0.4 \mathrm{~s}$, at start of filling) to $8 \mathrm{mmHg}$ at $0.44 \mathrm{~s}$.

thereafter decreases and becomes zero during diastolic filling. On the other hand $\mathrm{LV} \mathrm{E}_{\mathrm{p}}$ starts increasing after the initiation of $\mathrm{LV}$ filling as the $\mathrm{LV}$ volume increases. It reaches its maximum value at the end-of-filling phase, remains constant during isovolumic contraction, and thereafter decreases during ejection (as the LV volume decreases). While the generation of $\mathrm{E}_{\mathrm{a}}$ helps us to explain the development of the LV pressure increase during isovolumic contraction, the decrease of $\mathrm{E}_{\mathrm{a}}$ during diastole helps us to explain the decrease in LV pressure during early filling. The incorporation of both $E_{p}$ and $E_{a}$ helps us to explain the $\mathrm{LV}$ pressure changes during the filling and ejection phases.

\section{Methods}

\section{Data acquisition}

The subjects in this study were studied in a resting recumbent (baseline) state, after premedication with 100-500 mg of sodium pentobarbital by retrograde aortic catheterization. Left ventricular chamber pressure was measured by a pigtail catheter and Statham P23Eb pressure transducer; the pressure was recorded during ventriculography. Angiography was performed by injecting 30-36 ml of $75 \%$ sodium diatrizoate into the $\mathrm{LV}$ at 10 to $12 \mathrm{ml} / \mathrm{s}$. It has been found by using biplane angiocardiograms that calcu-

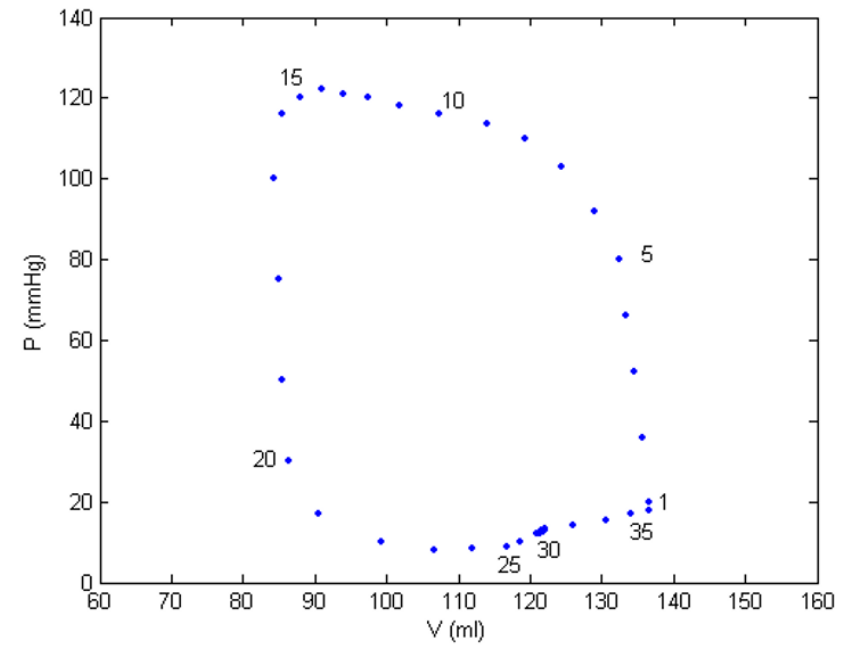

Figure 3

Relationship between LV volume and pressure for the data of figure 2. Relationship between LV volume and pressure for the data of Figure I. Points $(2 \mathrm{I}-36)$ constitute the filling phase, $(\mathrm{I}-5)$ constitute the isovolumic contraction phase, (5-17) constitute the ejection phase, and (I7-2I) constitute the isovolumic relaxation phase. Note that after point $2 \mathrm{I}$, the LV pressure decreases; this characterizes LV suction effect.

lated orthogonal chamber diameters are nearly identical [16]. These findings are used to justify the use of singleplane cine techniques, which allow for beat-to-beat analysis of the chamber dimensions.

For our study, monoplane cineangiocardiograms were recorded in a RAO $30^{\circ}$ projection from a 9 in image intensifier using $35 \mathrm{~mm}$ film at 50 frames/s using INTEGRIS Allura 9 system at the Nation Heart Centre (NHC), Singapore. Automated LV analysis was carried out to calculate LV volume and myocardial wall thickness. The LV data, derived from the cineangiographic films and depicted in Figure 2 consists of measured volume and myocardial thickness of the chamber as well as the corresponding pressure. All measurements are corrected for geometric distortion due to the respective recordings systems.

In Figure 2, it is noted that during the early filling phase, LV pressure decreases even though LV volume increases. This phenomenon is defined as the 'LV suction effect', which will be explained later by using our concepts of active and passive elastances. This phenomenon is also depicted in Figure 3 and Table 1. 
Table I: Computed values of $E_{a}$ and $E_{p}$ during the cardiac cycle, for subject $H E L$

\begin{tabular}{|c|c|c|c|c|c|c|}
\hline Point & Phase & Time & Pressure & Volume & $E_{a}$ & $E_{p}$ \\
\hline I & Isovolumic contraction & 0 & 18 & 136.7 & 0 & 0.968314 \\
\hline 2 & & 0.02 & 22 & 135.7 & 0.051287 & 0.930811 \\
\hline 3 & & 0.04 & 32 & 134.6 & 0.153167 & 0.891234 \\
\hline 4 & & 0.06 & 52 & 133.5 & 0.282331 & 0.853339 \\
\hline 5 & & 0.08 & 80 & 132.5 & 0.424912 & 0.820289 \\
\hline 6 & Ejection & 0.1 & 94 & 129 & 0.570602 & $0.7 \mid 4374$ \\
\hline 7 & & 0.12 & 103 & 124.5 & 0.711775 & 0.598039 \\
\hline 8 & & 0.14 & 110 & 119.3 & 0.843116 & 0.486996 \\
\hline 9 & & 0.16 & 113 & 114 & 0.961299 & 0.395008 \\
\hline 10 & & 0.18 & 116 & 107.3 & 1.06464 & 0.303159 \\
\hline 11 & & 0.2 & 118 & 101.8 & 1.15275 & 0.243961 \\
\hline 12 & & 0.22 & 120 & 97.5 & 1.22616 & 0.205852 \\
\hline 13 & & 0.24 & 121 & 94 & 1.28607 & 0.179272 \\
\hline 14 & & 0.26 & 122 & 91 & 1.334 & 0.159239 \\
\hline 15 & & 0.28 & 120 & 88 & 1.37114 & 0.141444 \\
\hline 16 & & 0.3 & 116 & 85.5 & 1.34002 & $0.128 \mid 44$ \\
\hline 17 & & 0.32 & 100 & 84.3 & 1.15107 & 0.122212 \\
\hline 18 & Isovolumic relaxation & 0.34 & 74 & 85 & $0.8464 I I$ & 0.125638 \\
\hline 19 & & 0.36 & 50 & 85.5 & 0.523931 & 0.128144 \\
\hline 20 & & 0.38 & 30 & 86.4 & 0.269515 & 0.132782 \\
\hline 21 & & 0.4 & 17 & 90.6 & 0.113989 & 0.156743 \\
\hline 22 & Filling & 0.42 & 10 & 105 & 0.0392726 & 0.27683 I \\
\hline 23 & & 0.44 & 8 & 112 & 0.0109316 & 0.365003 \\
\hline 24 & & 0.46 & 8.4 & 117 & 0.00244008 & 0.444703 \\
\hline 25 & & 0.48 & 9 & 119 & 0.00043378 & 0.481259 \\
\hline 26 & & 0.5 & 9.6 & 120.2 & 6. $10272 \mathrm{e}-005$ & 0.50462 \\
\hline 27 & & 0.52 & 10.2 & 121 & $6.75442 \mathrm{e}-006$ & 0.520821 \\
\hline 28 & & 0.54 & 10.5 & 121.4 & $5.84848 \mathrm{e}-007$ & 0.529115 \\
\hline 29 & & 0.56 & 10.7 & 121.6 & $3.94098 \mathrm{e}-008$ & 0.533312 \\
\hline 30 & & 0.58 & 10.8 & 121.8 & $2.0564 \mathrm{e}-009$ & 0.537542 \\
\hline 31 & & 0.6 & 11 & 122 & $8.2698 \mathrm{e}-01 \mathrm{I}$ & 0.541805 \\
\hline 32 & & 0.62 & 11.8 & 124 & $2.55156 \mathrm{e}-012$ & 0.586344 \\
\hline 33 & & 0.64 & 12.8 & 127 & $6.01397 \mathrm{e}-014$ & 0.66011 \\
\hline 34 & & 0.66 & 14.5 & 130.7 & $1.07837 e-015$ & 0.763991 \\
\hline 35 & & 0.68 & 17 & 134 & $1.46518 \mathrm{e}-017$ & 0.87036 \\
\hline 36 & & 0.7 & 20 & 136.6 & $1.50271 \mathrm{e}-019$ & 0.964497 \\
\hline 37 & & 0.72 & 18 & 136.7 & I.15909e-02I & 0.968314 \\
\hline
\end{tabular}

\section{Definition of passive elastance and active elastance of the LV}

At the start of diastolic-filling phase, the LV incremental pressure $\mathrm{dP}_{\mathrm{LV}}$ is the response to (i) $\mathrm{LV} \mathrm{E}$ a continuing to decrease due to the sarcomere continuing to relax well into the filling phase, and (ii) to the rapid inflow of blood and the corresponding increase in LV volume, along with increase in $\mathrm{LV} \mathrm{E}_{\mathrm{p}}$. The associated governing differential equation, relating LV pressure and volume, can be put down (by referring to the Appendix for its derivation) as [17]:

$M(d \dot{V})+d(E V)=M(d \dot{V})+V d E+E d V=d P_{L V}$ where $t$ represents the time variable (s) from the start of filling phase;

$V$ represents the volume of $\mathrm{LV}(\mathrm{ml})$ during the filling phase;

$P_{L V}$ represents pressure of the $\mathrm{LV}$, in $\mathrm{mmHg}$ (hereafter symbolized by $P$ ) ( $\mathrm{mmHg})$;

$M$ represents the inertia term $=[\mathrm{LV}$ wall-density $(\rho) /(\mathrm{LV}$ surface-area/wall-thickness) $]=\rho h / 4 \pi R^{2}$, for a spherical $\mathrm{LV}$ model (in $\mathrm{mmHg} /\left(\mathrm{ml} / \mathrm{s}^{2}\right)$ ); 
E represents LV elastance $(\mathrm{mmHg} / \mathrm{ml})$.

Likewise during ejection, the $\mathrm{LV}$ pressure variation $\left(\mathrm{dP}_{\mathrm{LV}}\right)$ is caused by both $\mathrm{E}_{\mathrm{a}}$ variation as well as $\mathrm{E}_{\mathrm{p}}$ decrease. The instantaneous time-varying ventricular elastance $(\mathrm{E})$ is the sum of (i) volume-dependent passive elastance $\left(E_{p}\right)$ and (ii) active elastance $\left(E_{a}\right)$ due to the activation of the LV sarcomere. Hence,

$E=E_{a}+E_{p}$

We will now provide the expressions for $\mathrm{E}_{\mathrm{p}}$ and $\mathrm{E}_{\mathrm{a}^{\prime}}$ and then their formulations. The passive (unactivated) myocardium exhibits properties of an elastic material, developing an increasing stress as strain increases, as occurs during ventricular filling. The passive stress-strain relation of myocardial muscle strip is nonlinear, and therefore cannot be described by Hooke's law. As an approximation, it follows an exponential relationship [18-20]. Therefore, the relation between LV passive pressure and volume has also been assumed to be exponential. Since $E_{p}(=d P / d V)$ is volume-dependent, we can express it as:

$E_{p}=(d P / d V)=E_{p 0} e^{z_{p} V}$

where $E_{p 0}$ is the passive elastance coefficient, $z_{p}$ is the passive elastance exponent, and V is the LV volume; its derivation is provided in a subsequent section.

On the other hand, we will represent $\mathrm{E}_{a}$ as an intrinsic property of the LV (derived later), as:

$E_{a}=E_{a 0}\left[1-e^{-\left(\frac{t}{\tau_{C}}\right)^{Z_{c}}}\right]\left[e^{-\left(\frac{(t-d) u(t-d)}{\tau_{R}}\right)^{Z_{R}}}\right]$

where (i) $t$ is measured from the start of isovolumic contraction, (ii) the parameter $E_{a 0}$ is the active elastance coefficient, (iii) the time-coefficient $\left(\tau_{C}\right)$ describes the rate of elastance rise during the contraction phase, while $\left(\tau_{R}\right)$ describes the rate of elastance fall during the relaxation phase; (iv) the exponents " $Z_{C}$ " and " $Z_{R}$ " are introduced to smoothen the curvatures of the $\mathrm{E}_{a}$ curve during isovolumic contraction and relaxation phases; (v) the parameter $\mathrm{d}$ is a time constant whose (to be determined) value is during the ejection phase, and $(\mathrm{vi}) \mathrm{u}(\mathrm{t}-\mathrm{d})$ is the unit step function, $\mathrm{u}(\mathrm{t}-\mathrm{d})=0$ for $\mathrm{t}<\mathrm{d}$. The rationale for equation (8), as provided in the next section, is based on $\mathrm{E}_{\mathrm{a}}$ incorporating parameters reflecting the (i) generation of LV pressure during isovolumic contraction, (ii) decrease of LV pressure during isovolumic relaxation and early filling, and (iii) the LV pressure-volume relationship during filling and ejection phase.

\section{Our hypothesis}

Based on equations (5-8), our hypothesis is that both $E_{a}$ and $\mathrm{E}_{\mathrm{p}}$ contribute to the relationship of LV pressure and volume. While $\mathrm{E}_{\mathrm{p}}$ incorporates $\mathrm{LV}$ pressure change due to $\mathrm{LV}$ volume change, $\mathrm{E}_{\mathrm{a}}$ incorporates the effect of $\mathrm{LV}$ myocardial activation in the generation of $\mathrm{LV}$ pressure during the isovolumic phases (when the LV volume remains constant). Since $\mathrm{E}_{\mathrm{a}}$ is deemed to be the basis of $\mathrm{LV}$ pressure generation, its variation (as given by equation 8) corresponds to the $\mathrm{LV}$ pressure variation.

\section{Determination of $E_{a}$ and $E_{p}$ expressions}

a) Active elastance (during isovolumic contraction and relaxation)

During isovolumic contraction (because $\mathrm{dV}=0, d \dot{V}=0$ and $E_{p}$ is constant), the governing equation (5) becomes $V d E=d P_{L V}$, which can be detailed as:

$V_{i}\left(E_{i}-E_{i-1}\right)=V_{i}\left[\left(E_{a, i}+E_{p, i}\right)-\left(E_{a, i-1}+E_{p, i-1}\right)\right]=V_{i}\left(E_{a, i}+E_{p e d}-\right.$ $\left.E_{a, i-1}-E_{p e d}\right)=d P_{L V, i}$

where $i$ is a time instant during the isovolumic contraction and relaxation, $V_{i}$ and $P_{L V, i}$ are the monitored $L V$ volume and pressure at this instant, and $\mathrm{E}_{\mathrm{ped}}$ is the passive elastance at the end-diastolic phase.

Also, during isovolumic relaxation (because $\mathrm{dV}=0$, $d \dot{V}=0$ and $\mathrm{E}_{\mathrm{p}}$ is constant), the governing equation (5) becomes $V d E=d P_{L V^{\prime}}$, which can be represented as:

$V_{i}\left(E_{a, i}+E_{p, i}-E_{a, i-1}-E_{p, i-1}\right)=V_{i}\left(E_{a, i}+E_{p e s}-E_{a, i-1}-E_{p e s}\right)=d P_{L V, i}$ (10)

where $\mathrm{E}_{\mathrm{pes}}$ is the passive elastance at the end-systolic phase

Now, applying equations $(9 \& 10)$ to the case shown in the Figure 2, we have (using the monitored LV pressurevolume data):

\section{For isovolumic contraction}

$E_{a, 1}=0 \quad(11-\mathrm{a})$

$E_{a, 2}=\left(P_{2}-P_{1}\right) / V_{2}+E_{a, 1}=0.029477 \mathrm{mmHg} / \mathrm{ml}$

$E_{a, 3}=\left(P_{3}-P_{2}\right) / V_{3}+E_{a, 2}=0.103771 \mathrm{mmHg} / \mathrm{ml}$

$E_{a, 4}=\left(P_{4}-P_{3}\right) / V_{4}+E_{a, 3}=0.253584 \mathrm{mmHg} / \mathrm{ml}$

$E_{a, 5}=\left(P_{5}-P_{4}\right) / V_{5}+E_{a, 4}=0.463599 \mathrm{mmHg} / \mathrm{ml}$

\section{For isovolumic relaxation}

$E_{a, 18}=\left(P_{18}-P_{17}\right) / V_{18}+E_{a, 17}=E_{a, 17}-0.058954 \mathrm{mmHg} / \mathrm{ml}$ (11-f) 


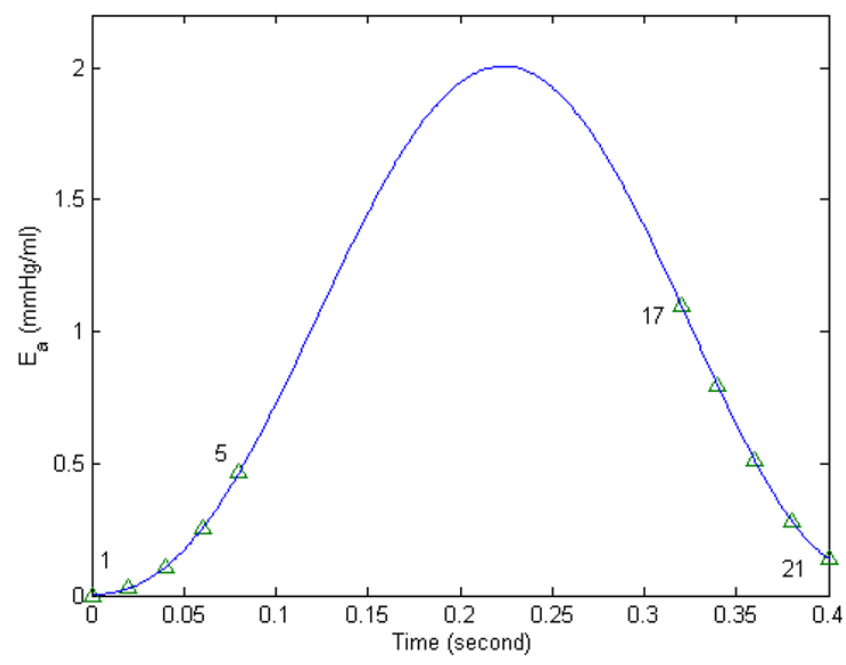

Figure 4

$E_{a}$ vs. time for the data of figure 2. Points $(I-5)$ are the computed values of $E_{a}$ during isovolumic contraction phase, based on equations II (a-e). In the isovolumic relaxation phase, the computed values are represented by the symbol $\Delta$, for $E_{a, 17}=1.1 \mathrm{mmHg} / \mathrm{ml}$. The best fit for $E_{a}$ during isovolumic contraction and relaxation phase is given by the curve: $E_{a}$ $=-12000 t^{6}+17000 t^{5}-7700 t^{4}+1100 t^{3}+19 t^{2}+0.59 t+$ 0.00056

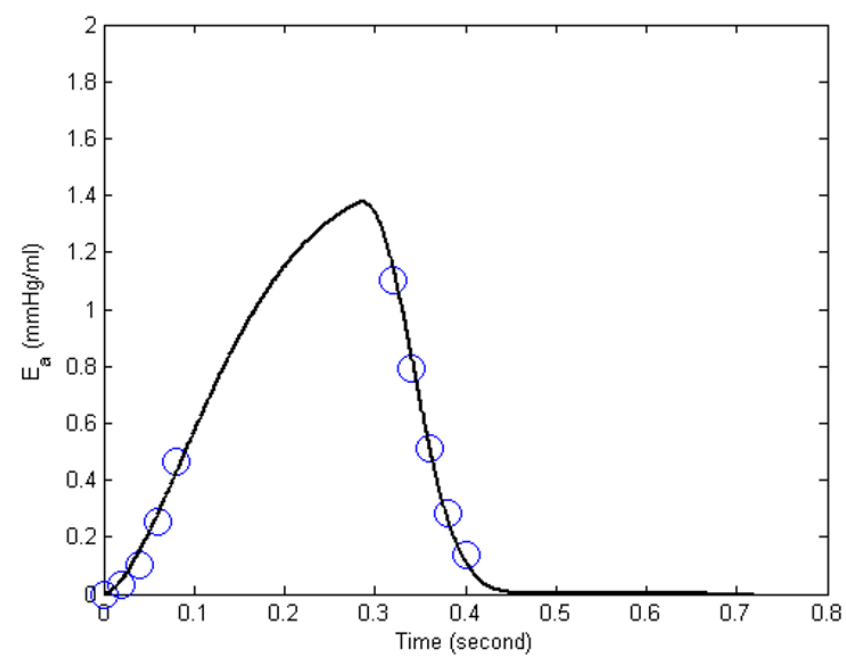

Figure 5

The data of figure 2 is fitted with equation (8). When the patient data of Figure 2 is fitted with equation (8), the resulting parameters values are obtained as: $E_{a 0}=1.48$ $\mathrm{mmHg} / \mathrm{ml}, \tau_{C}=0.1555 \mathrm{~s}, Z_{C}=1.63 \mathrm{I}, \mathrm{d}=0.28 \mathrm{~s}, \tau_{R}=0.07935$ $\mathrm{s}, Z_{R}=2.267 \mathrm{~s}, E_{a, 17}=1.1 \mathrm{mmHg} / \mathrm{ml}, \mathrm{RMS}=0.026 \mathrm{mmHg} / \mathrm{ml}$.
$E_{a, 19}=\left(P_{19}-P_{18}\right) / V_{19}+E_{a, 18}=E_{a, 17}-0.177824 \mathrm{mmHg} / \mathrm{ml}$ (11-g)

$E_{a, 20}=\left(P_{20}-P_{19}\right) / V_{20}+E_{a, 19}=E_{a, 17}-0.312656 \mathrm{mmHg} / \mathrm{ml}$ (11-h)

$E_{a, 21}=\left(P_{21}-P_{20}\right) / V_{21}+E_{a, 20}=E_{a, 17}-0.463599 \mathrm{mmHg} / \mathrm{ml}$ (11-i)

Now in the above expressions $11(\mathrm{f}-\mathrm{i}), \mathrm{E}_{\mathrm{a}, 17}$ at end-ejection is unknown. For different representative values of $\mathrm{E}_{\mathrm{a}, 17}$, we can get different $\mathrm{E}_{\mathrm{a}}$ curves. We need to determine the optimal value of $\mathrm{E}_{\mathrm{a}, 17}$, such that $\mathrm{E}_{\mathrm{a}}$ can be described by $\mathrm{a}$ smooth curve to fit both isovolumic contraction and ejection phases. In Figure 4, we have determined $\mathrm{E}_{\mathrm{a}, 17}=1.1$ $\mathrm{mmHg} / \mathrm{ml}$, and the polynomial expression for $\mathrm{E}_{\mathrm{a}}(\mathrm{t})$ to fit its above calculated values during isovolumic contraction and relaxation. However, in order to (i) more suitably represent $\mathrm{E}_{\mathrm{a}}$ to correspond with its role during the cardiac phases (isovolumic, ejection and filling), and (ii) because of the sigmoidal shape of $\mathrm{E}_{\mathrm{a}}$ curve and its variation resembling the LV pressure variation during systole (as seen in Figure 4), we express $\mathrm{E}_{\mathrm{a}}$ (according to equation 8 ) as:

$E_{a}=E_{a 0}\left[1-e^{-\left(\frac{t}{\tau_{C}}\right)^{Z_{c}}}\right]\left[e^{-\left(\frac{(t-d) u(t-d)}{\tau_{R}}\right)^{Z_{R}}}\right]$

So that its constituent parameters have physiological significance as indicated following equation (8).

Hence, to compute $\mathrm{E}_{\mathrm{a}}(\mathrm{s})$ during isovolumic contraction, when $\mathrm{u}(\mathrm{t}-\mathrm{d})=0$, we employ the expression

$E_{a}=E_{a 0}\left[1-e^{-\left(\frac{t}{\tau_{C}}\right)^{Z_{c}}}\right]$

and determine its parameters $\mathrm{E}_{\mathrm{a} 0}, \tau_{\mathrm{C}}$ and $\mathrm{Z}_{\mathrm{C}}$ to fit the monitored pressure-volume data. Then, to compute $\mathrm{E}_{\mathrm{a}}(\mathrm{s})$ during isovolumic relaxation, we employ the total expression

$E_{a}=E_{a 0}\left[1-e^{-\left(\frac{t}{\tau_{C}}\right)^{Z_{c}}}\right]\left[e^{-\left(\frac{(t-d) u(t-d)}{\tau_{R}}\right)^{Z_{R}}}\right]$

and determine its remaining parameters $d, \tau_{R}$ and $Z_{R}$ to fit the measured pressure-volume data.

For the sample data of Figure 2, the variation of $\mathrm{E}_{\mathrm{a}}$ is depicted in Figure 5, along with the values of its parameters. We now propose that $\mathrm{E}_{\mathrm{a}}$ can be employed as an index of contractility.

b) Passive elastance determination during diastolic filling During the diastolic filling phase, equation (5) becomes 


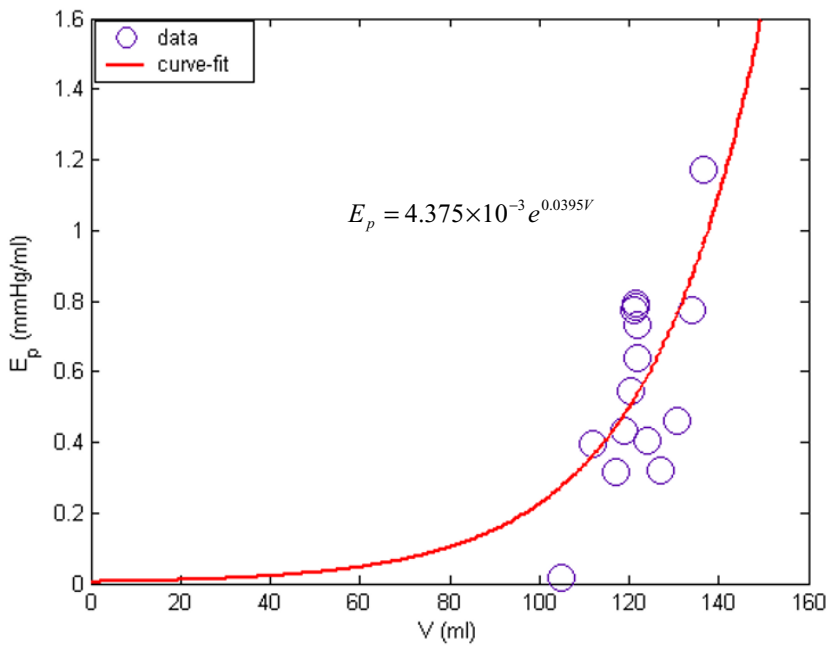

Figure 6

Passive elastance $E_{p}$ vs LV volume for the data of figure 2. Passive elastance $E_{p}$ vs $L V$ volume $V$, for the sample case shown in Figure 2.

$$
\begin{array}{r}
M\left(d \dot{V}_{i}\right)+V_{i}\left[\left(E_{a, i}+E_{p, i}\right)-\left(E_{a, i-1}+E_{p, i-1}\right)\right]+\left(E_{p, i}+E_{a, i}\right)\left(V_{i}-V_{i-1}\right)=P_{i}-P_{i-1} \\
\operatorname{or}, M\left(d \dot{V}_{i}\right)+V_{i}\left[\left(E_{a, i}-E_{a, i-1}\right)+\left(E_{p, i}-E_{p, i-1}\right)\right]_{@ t_{i}}+\left(E_{p, i}+E_{a, i}\right)\left(V_{i}-V_{i-1}\right)=P_{i}-P_{i-1}
\end{array}
$$

Now because $E_{p}$ is constant at a particular volume $V_{i^{\prime}}$ equation (13) becomes

$M\left(d \dot{V}_{i}\right)+V_{i}\left(E_{a, i}-E_{a, i-1}\right)+\left(E_{p, i}+E_{a, i}\right)\left(V_{i}-V_{i-1}\right)=P_{i}-P_{i-1}$

$\therefore E_{p, i}=\frac{\left(P_{i}-P_{i-1}\right)-M\left(d \dot{V}_{i}\right)-V_{i}\left(E_{a, i}-E_{a, i-1}\right)}{V_{i}-V_{i-1}}-E_{a, i}$

where $\mathrm{i}$ is a time-instant during diastolic filling, $\mathrm{V}_{\mathrm{i}}$ and $\mathrm{P}_{\mathrm{LV}, \mathrm{i}}$ are the monitored $\mathrm{LV}$ volume and pressure at this time, and $M=\rho h / 4 \pi R^{2}$. For the patient data (shown in Figure 2), we can get the mean value for $\mathrm{M}$ during diastolic filling, $M=8.03 \times 10^{-6} \mathrm{mmHg} /\left(\mathrm{ml} / \mathrm{s}^{2}\right)$. Therefore, from equation (15), we can calculate the values of $\mathrm{E}_{\mathrm{p}}$ at various instants during filling phase. We then plot $E_{p} v s V$, in Figure 6. By fitting equation (7) to these calculated values of $E_{p^{\prime}}$, we obtain the values of the parameters $E_{p 0}$ and $z_{p}$ as:

$z_{p}=0.0395 \mathrm{ml}^{-1}, E_{p 0}=4.375 \times 10^{-3} \mathrm{mmHg} / \mathrm{ml}$

and the $\mathrm{E}_{\mathrm{p}}$ function (corresponding to its expression given by equation 7) as follows:

$E_{p}=4.375 \times 10^{-3} e^{0.0395 \mathrm{~V}}$
We now propose to adopt $\mathrm{E}_{\mathrm{p}}$ as a measure of $\mathrm{LV}$ resistanceto-filling.

Hence during ejection, both $\mathrm{E}_{\mathrm{a}}$ and $\mathrm{E}_{\mathrm{p}}$ are varying. During ejection and filling phases, $E_{p}$ can be calculated at any time using equation (17). Likewise, $\mathrm{E}_{\mathrm{a}}$ can be calculated during ejection and filling phases using equation (8), once its parameters have been determined by employing equation (12-b \& 12-b) during isovolumic contraction and relaxation phases. Their values during the cardiac cycle are listed in Table 1.

\section{Clinical application results}

The analyses, presented herewith, are now applied to clinically obtained data consisting of the subject's left ventricular (instant-to-instant) dimensions (obtained by cineangiocardiograph) and chamber pressure (obtained by cardiac catheterization). For each subject, passive and active elastances are determined from the left ventricular data. Table 2 provides the measured data and the modelderived parameters for three subjects (subject HEL, DDM, and ML). Subject HEL serves as a sample patient with myocardial infarct, subject DDM with double vessel disease (DVD) and hypertension, treated with PTCA; subject ML with idiopathic myocardial hypertrophy (IMH).

The variations of model-derived nonlinear passive and active elastances for the subject HEL are shown in Figure 7. For this particular subject (HEL), the maximum active elastance is $1.37 \mathrm{mmHg} / \mathrm{ml}$. In Figure 8, we have plotted $\mathrm{E}_{\mathrm{a}}$ vs incremental pressure (P-P $\mathrm{P}_{\mathrm{ed}}$ ) for this patient HEL. Note that the elastance is much higher at late-ejection than early ejection. This is because of a continuing sarcomere stress development and shortening. The active elastance reaches its maximum value at late-ejection (point 15), and thereafter decreases. However as shown in Figure 7 , even after the end of relaxation phase (point 21) the active elastance continue to decrease into the filling phase. This decrease can explain the suction effect during the rapid filling sub-phase, even after LV filling has commenced.

Figures 9 and 10 provide representations of the nonlinear passive and active elastance for subject HEL (with hypertension), DDM (myocardial infarct), and ML (idiopathic myocardial hypertrophy). The $\mathrm{E}_{\mathrm{p}} \mathrm{vs} \mathrm{LV}$ volume plots, in Figure 9, clearly reveal that $E_{p}$ increases exponentially with increase $\mathrm{LV}$ volume; the parameters $\left(E_{P 0}\right.$ and $\left.z_{p}\right)$ characterize this relationship. The passive elastance curve is steeper for a stiffer myocardium, with a corresponding bigger value of the exponential coefficient $Z_{p}$ (subject ML). The $\mathrm{E}_{\mathrm{a}}$ vs incremental pressure ( $\left.\mathrm{P}-\mathrm{P}_{\mathrm{ed}}\right)$ plots, in Figure 10, reveal the development and decrease of $\mathrm{E}_{\mathrm{a}}$ during systole, which in turn governs the generation of LV pressure. 
Table 2: Clinical history, measured hemodynamic data and calculated passive and active elastance parameters $\left(E_{p}\right.$ and $\left.E_{a}\right)$ for subjects (HEL, DDM and ML). Where LVP: left ventricle chamber pressure, AOP: aortic pressure, EDV: end-diastolic volume, ESV: end-systolic volume, EF: ejection fraction, MI: myocardial infarct, DVD: double vessel disease, HTN: hypertension, IMH: idiopathic myocardial hypertrophy, $E_{a, \max }:$ maximum active elastance

\begin{tabular}{llll}
\hline Subject & H.E.L & D.D.M & M.L \\
\hline Disease & MI, DVD & DVD, HTN & IMH \\
LVP $(\mathrm{mmHg})$ & $122 / 18$ & $170 / 24$ & $109 / 12$ \\
AOP $(\mathrm{mmHg})$ & $125 / 75$ & $169 / 99$ & $115 / 70$ \\
EDV/ESV $(\mathrm{ml})$ & $132.5 / 84.3$ & $121.7 / 41.3$ & $368 / 284$ \\
EF & 0.36 & 0.66 & 0.23 \\
$E_{p 0}(\mathrm{mmHg} / \mathrm{ml})$ & $4.375 \times 10^{-3}$ & $6.74 \times 10^{-5}$ & $1.442 \times 10^{-8}$ \\
$Z_{p}\left(\left.\mathrm{ml}\right|^{-1}\right)$ & 0.0395 & 0.07499 & 0.05024 \\
$E_{a 0}(\mathrm{mmHg} / \mathrm{ml})$ & 1.48 & 4.4 & 0.595 \\
$\tau_{C}(\mathrm{~s})$ & 0.1555 & 0.207 & 0.1082 \\
$Z_{C}$ & 1.631 & 1.536 & 1.977 \\
$d(\mathrm{~s})$ & 0.28 & 0.26 & 0.18 \\
$\tau_{R}(\mathrm{~s})$ & 0.07935 & 0.1536 & 0.1377 \\
$Z_{R}$ & 2.267 & 2.943 & 1.873 \\
$E_{a, \max }(\mathrm{mmHg} / \mathrm{ml})$ & 1.37 & 3.58 & 0.57 \\
$d P / d t_{\max }(\mathrm{mmHg} / \mathrm{s})$ & 1200 & 1475 & 1125
\end{tabular}

\section{Discussion}

\section{Ea as a contractility index}

Yet another way to study $\mathrm{E}_{\mathrm{a}}$ variation is by means of the $\mathrm{E}_{\mathrm{a}}$ vs normalized time $\left(\mathrm{t} / \mathrm{t}_{\mathrm{s}}\right)$ plot, shown in Figure 11 . These two figures 10 and 11 make us realize that $\mathrm{E}_{\mathrm{a} \text {, max }}$ could be regarded as an index of $\mathrm{LV}$ contractility. Hence, we decided to plot $\mathrm{E}_{\mathrm{a} \max }$ vs the traditional contractility indices of $\mathrm{EF}$ and $(\mathrm{dP} / \mathrm{dt})_{\max }$. These plots are displayed in Figures 12 and 13. It is noted that $\mathrm{E}_{\mathrm{a} \text {,max }}$ has a high degree of correlation with both $\mathrm{EF}$ and $(\mathrm{dP} / \mathrm{dt})_{\max }$. It is interesting to compare our correlation-coefficient value $(0.8972)$ with the value of 0.89 obtained by Mehmel et al [12], although this paper computes elastance as an extrinsic property = $\left[\mathrm{P} /\left(\mathrm{V}-\mathrm{V}_{\mathrm{d}}\right)\right]_{\text {es }}$.

\section{Demonstrating LV suction phenomenon}

The active elastance curve can explain some critical LV physiological phenomena, namely LV pressure generation during isovolumic contraction and LV suction during early filling. The rapid decrease in elastance during isovolumic relaxation extends into the filling phase, and can explain the decrease in LV pressure (in Figure 7) even after LV filling has commenced. Let us show how this happens, by rewriting equation (15) as follows:

$P_{i}-P_{i-1}=\left(E_{p, i}+E_{a, i}\right)\left(V_{i}-V_{i-1}\right)+V_{i}\left(E_{a, i}-E_{a, i-1}\right)$

by neglecting the $\mathrm{M}\left(\mathrm{d} \dot{\mathrm{V}}_{\mathrm{i}}\right)$ term, based on the calculation of its value being of the order of $10^{-2}$ compared to (i) $\left(E_{p, i}\right.$ $\left.+E_{a, i}\right)\left(V_{i}-V_{i-1}\right)$, which is of the order of $10^{0}$ and (ii) $V_{i}\left(E_{a, i}\right.$ - $\left.E_{a, i-1}\right)$ which is the order of $10^{1}$.
In equation (18), it is seen that $\mathrm{P}_{\mathrm{i}}$ can be less than $\mathrm{P}_{\mathrm{i}-1}$ (or that $\left.\mathrm{P}_{\mathrm{i}}-\mathrm{P}_{\mathrm{i}-1}<0\right)$ only if $\left(\mathrm{E}_{\mathrm{a}, \mathrm{i}}-\mathrm{E}_{\mathrm{a}, \mathrm{i}-1}\right)$ is negative, i.e., active elastance is decreasing. Now for subject H.E.L (Figure 1), the computed values of $\mathrm{E}_{\mathrm{a}}$ and $\mathrm{E}_{\mathrm{p}}$ at these 2 instants (based on equations 8 \& 17) are:

$E_{p, 22}=0.2768 \mathrm{mmHg} / \mathrm{ml}, E_{a, 22}=0.0393 \mathrm{mmHg} / \mathrm{ml}, E_{a, 21}=$ $0.1140 \mathrm{mmHg} / \mathrm{ml}, V_{22}=105 \mathrm{ml}, V_{21}=90.6 \mathrm{ml}$

Substituting these values into equation (18) gives $\left(P_{22}\right.$ $\left.P_{21}\right)=-3.22 \mathrm{mmHg}$, confirming decrease of pressure during early filling.

Hence, our novel concept of "decreasing $\mathrm{E}_{\mathrm{a}}$ during the early phase of filling" enables us to explain the phenomenon of decreasing LV pressure during the early stage of filling. In other words, it is suggested that the sarcomere actin-myosin activity continues into the filling phase. The decreasing $\mathrm{E}_{\mathrm{a}}$ during the filling phase seems to reflect decreasing sarcomeric activity during filling. Likewise, the increase in $\mathrm{E}_{\mathrm{a}}$ during isovolumic contraction is responsible for increase in LV pressure at constant volume, as demonstrated by means of equation (11).

\section{Demonstrating variation of $L V$ pressure during ejection in} terms of $E_{a}$ and $E_{p}$

Similarly, both the active and passive elastances can explain LV pressure variation during ejection, using equation (18). Let us show how this happens by just taking two instants $\left(\mathrm{t}_{10} \& \mathrm{t}_{9}\right)$, as follows:

$P_{10}-P_{9}=\left(E_{p, 10}+E_{a, 10}\right)\left(V_{10}-V_{9}\right)+V_{10}\left(E_{a, 10}-E_{a, 9}\right)$ 

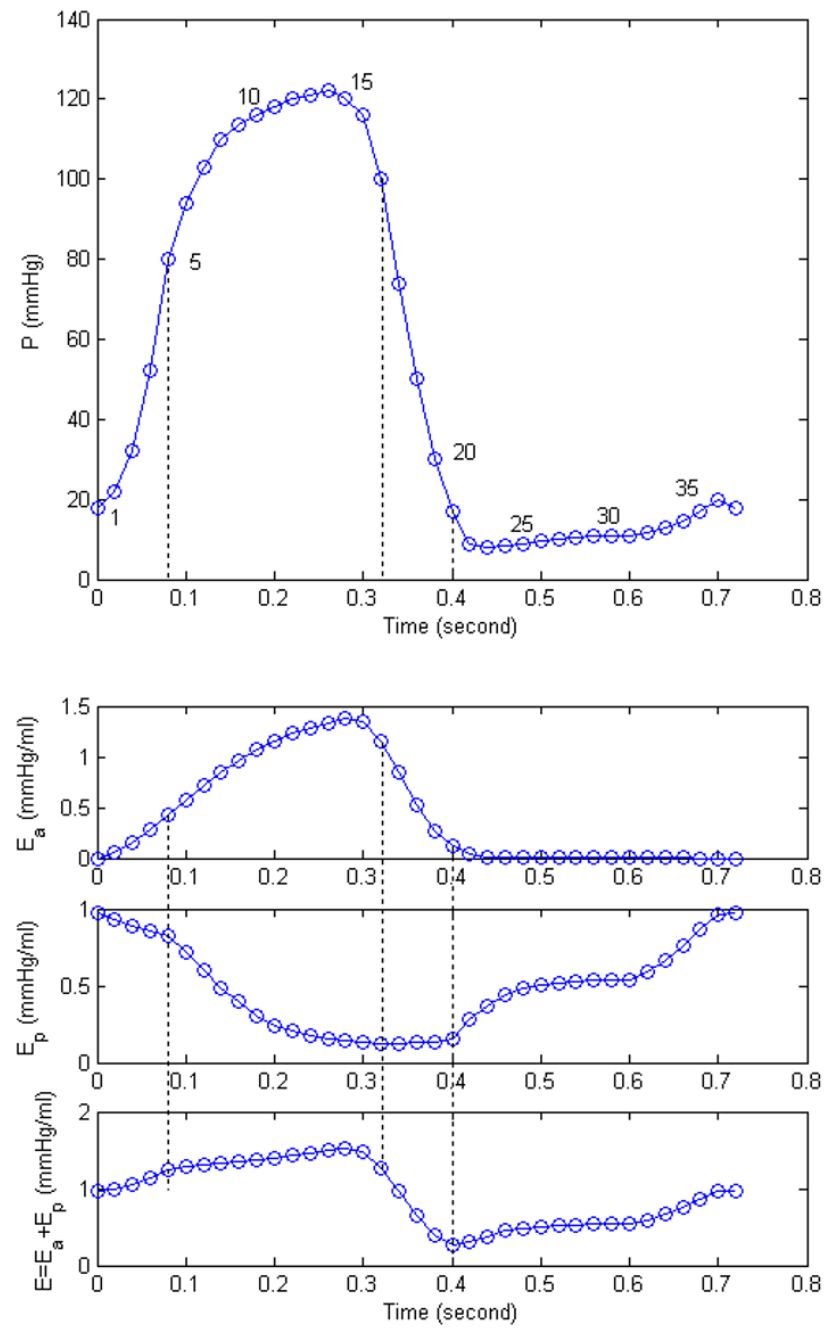

\section{Figure 7}

Pressure, active elastance $E_{a}$, and passive elastance $E_{p}$ and total $E=E_{a}+E_{p}$ for the data of figure 2. Pressure, active elastance $\mathrm{E}_{\mathrm{a}}$, passive elastance $\mathrm{E}_{\mathrm{p}}$, and total $E=$ $\left(E_{a}+E_{p}\right)$ for the sample subject shown in Figure 2. In this figure, $1-5$ represents the isovolumic contraction phase, 5-I7 represents the ejection phase, and |7-2| represents the isovolumic relaxation phase, 2 I-37 represents the diastolic filling phase.

Substituting these computed values (listed in Table 1) into equation (20) gives $P_{10}-P_{9}=1.92 \mathrm{mmHg}$, which is approximately equal to the actual value of $2 \mathrm{mmHg}$.

\section{Concluding comments}

Previous works have described elastance as a derived parameter from LV pressure-volume data, based on the definition of $P /\left(V-V_{d}\right)[9,10,12-14]$. Also, $\mathrm{E}_{\max }$ (given by

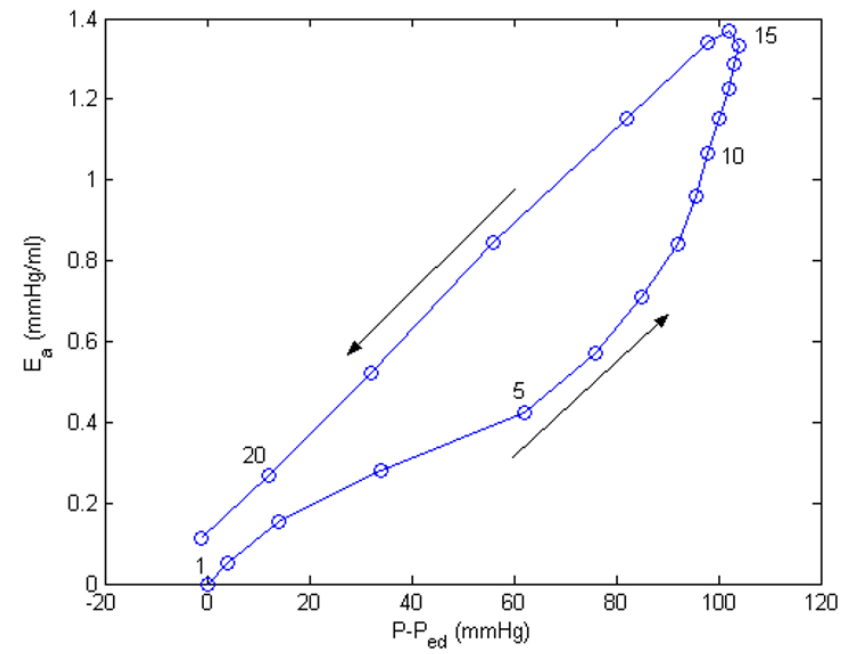

Figure 8

Active elastance vs. incremental pressure. Active elastance vs. incremental pressure $\left(P-P_{e d}\right)$ for the same subject as shown in Figure 2. The arrow direction indicates progression of time; 1-5: isovolumic contraction phase; 5-17: ejection phase. Note the rapid decrease in $E_{a}$ during the isovolumic relaxation that also extends into the filling phase, and causes suction of blood into the LV even before initiation of left-atrial contraction.

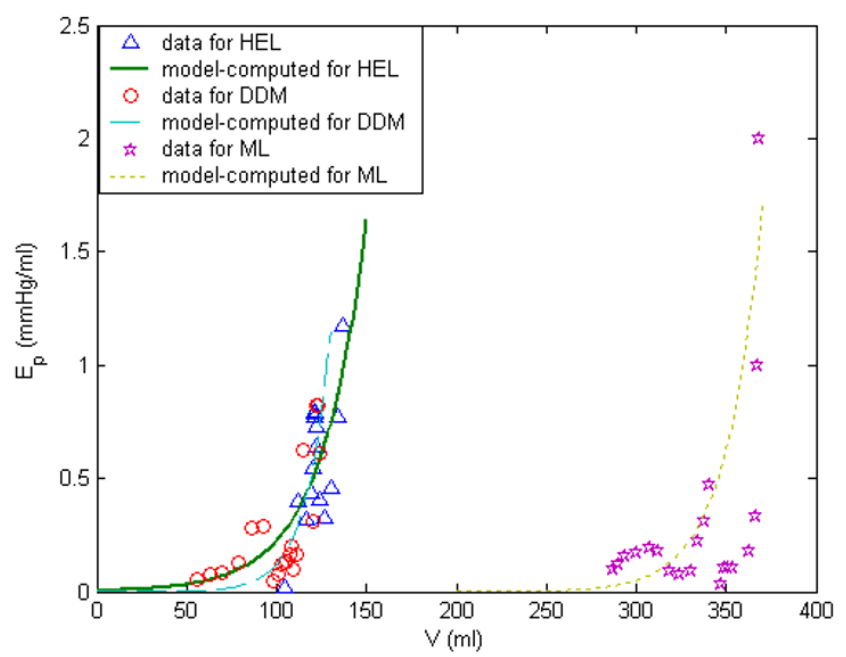

Figure 9

LV volume and corresponding volume-dependent passive elastance. Volume-dependent passive elastance $\left(E_{p}\right)$ for subjects HEL, DDM, and ML.

ESPVR) as illustrated on Figure 1 varies with different arterial loading states and is therefore load dependent [21], 


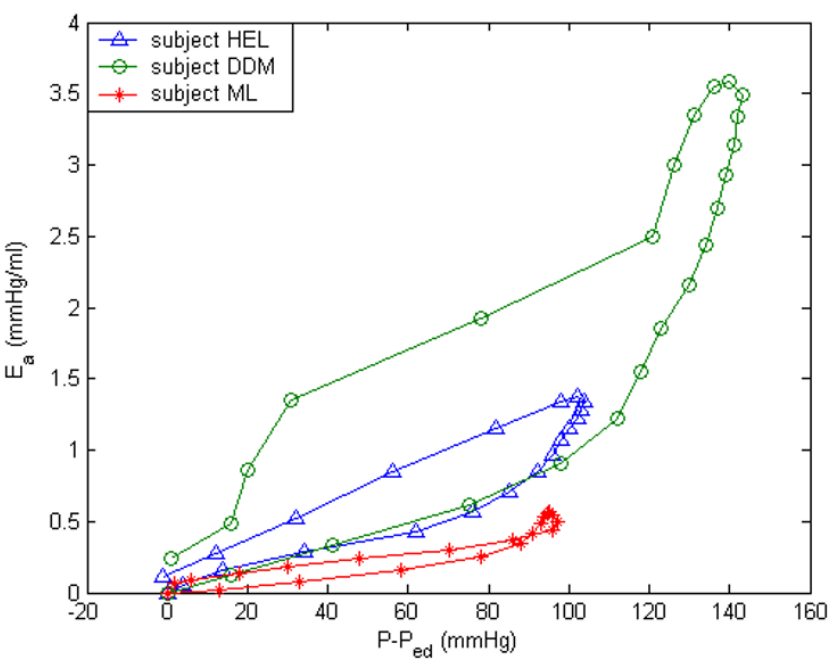

Figure 10

Active elastance vs. incremental pressure. Active elastance vs. incremental pressure for subjects HEL, DDM, and ML.

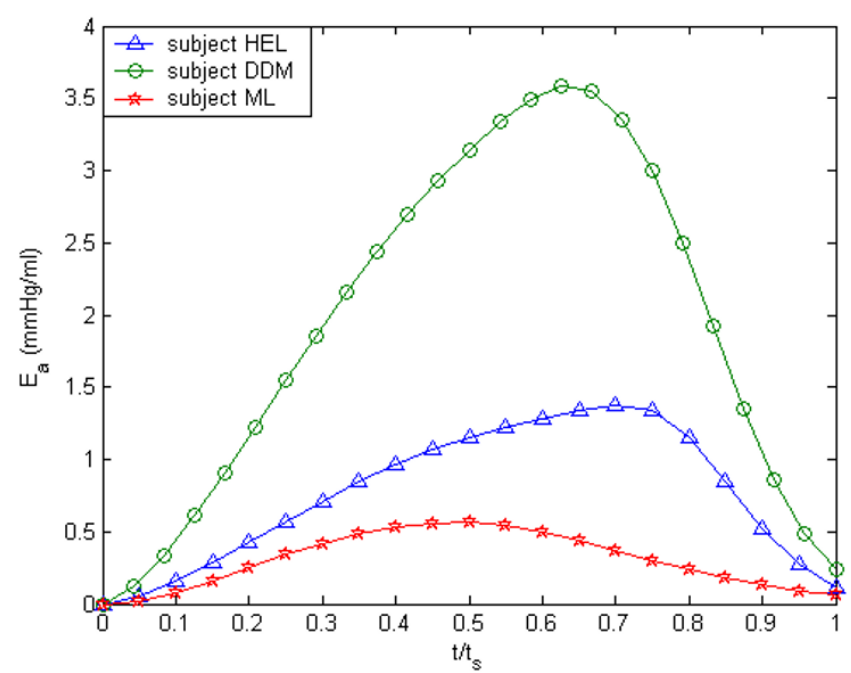

Figure I I

Active elastance vs. normalized time. Active elastance vs normalized time $\left(t / t_{s}\right)$ for subjects HEL, DDM, and $M L$. Herein, $t_{s}$ is the duration from start-of-isovolumic contraction phase to end-of-isovolumic relaxation.

and not an intrinsic index independent of LV loading states.

Our definitions of $\mathrm{E}_{\mathrm{p}}$ and $\mathrm{E}_{\mathrm{a}}$ enable us to explain the phenomena of (i) LV suction during early filing, (ii) LV

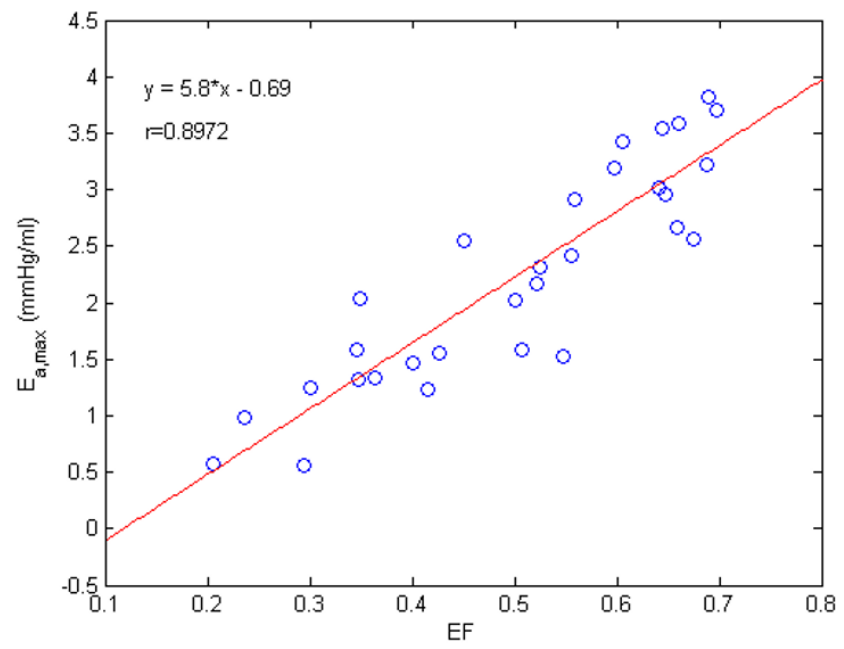

Figure 12

$\mathbf{E}_{a, \max }$ vs EF. Relating our contractility index $E_{a, \max }$ to $E F$ factor, with $r$ being the correlation coefficient.

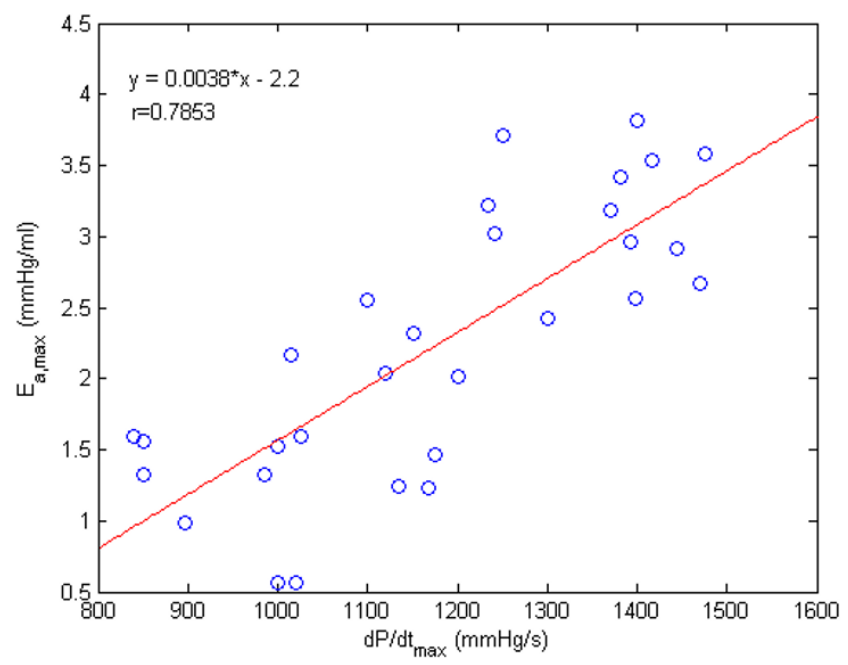

\section{Figure 13}

$\mathbf{E}_{\mathbf{a}, \max } \mathbf{v s} \mathbf{d P / d t _ { \text { max } }}$. Relating our contractility index $E_{a, \max }$ to the traditional contractility index $\mathrm{dP} / \mathrm{dt}_{\max }$, with $\mathrm{r}$ being the correlation coefficient. pressure rise during isovolumic contraction (iii) LV pressure variation during the ejection phase, and (iv) LV pressure drop during the relaxation phase. Both the concepts of $\mathrm{E}_{\mathrm{a}}$ and $\mathrm{E}_{\mathrm{p}}$ are made possible by our redefining elastance and compliance as 

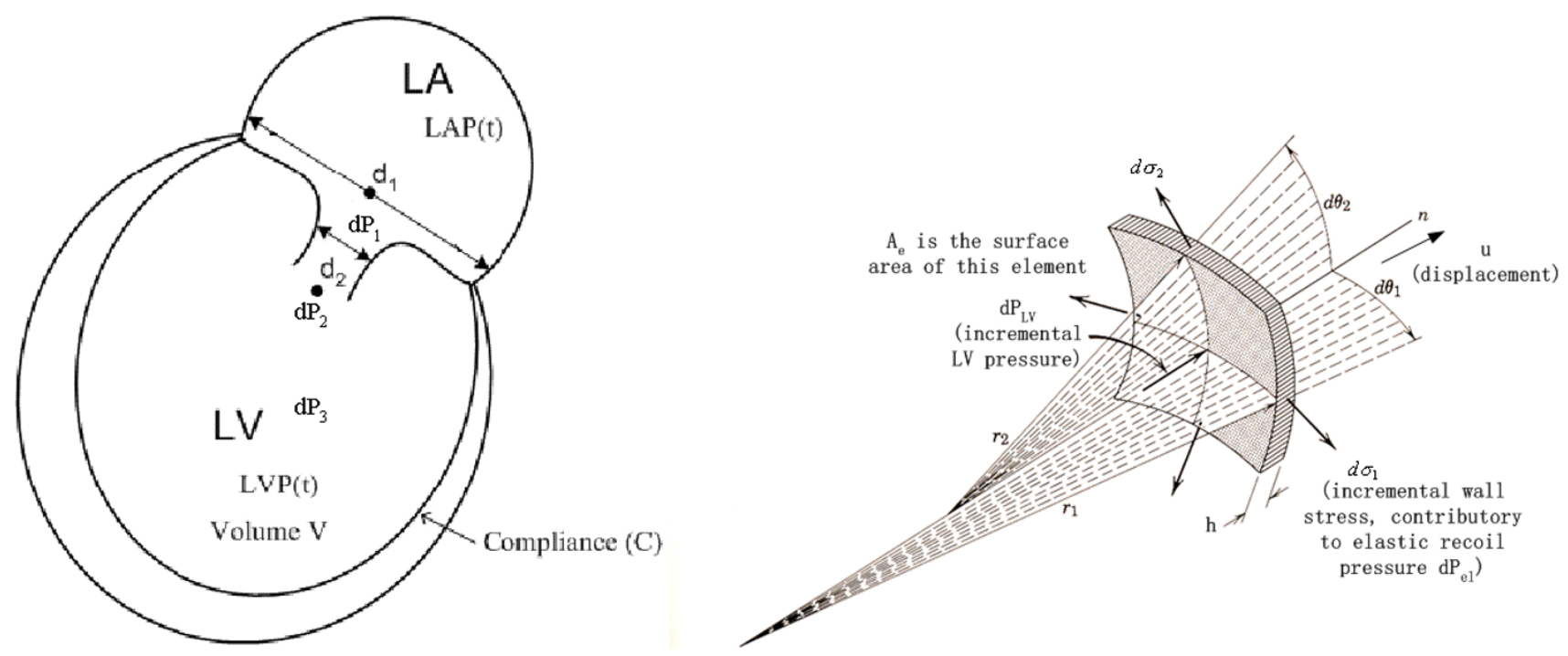

Figure 14

Dynamic equilibrium of a myocardial element. Dynamic equilibrium of a myocardial element. Element mass $m_{\mathrm{e}}=$ $\rho\left(2 r_{1} d \theta_{1}\right)\left(2 r_{2} d \theta_{2}\right) h=(\rho h)\left(4 r_{1} r_{2} d \theta_{l} \theta_{2}\right)=\rho h A_{e}=m_{s} A_{e} ; d \sigma_{i}=\left(d P_{e l}\right)\left(r_{i}\right) /(2 h),(i=I, 2) ; d P_{e l}$ is the incremental elastic-recoil pressure.

For dynamic equilibrium of the myocardial element, $m_{\mathrm{e}} d \dot{u}+2\left(d \sigma_{1}\right)\left(2 r_{2} d \theta_{2} h\right)+2\left(d \sigma_{2}\right)\left(2 r_{1} d \theta_{1} h\right)-A_{\mathrm{e}} d P_{L V}=0$, or $m_{\mathrm{e}} d \dot{u}+A_{\mathrm{e}} d P_{\mathrm{el}}-$ $A_{e} d P_{L V}=0$. For our LV spherical geometry model, $r_{1}=r_{2}$ and $d \sigma_{1}=d \sigma_{2}$.

$d P=d(E V)=d(V / C)=V d E+E d V$

Our concept of $\mathrm{E}_{\mathrm{a}}$ enables us to explain (i) the generation of pressure during isovolumic contraction and decrease of pressure during isovolumic relaxation, when the volume is constant, and (ii) the decrease of pressure during the rapid filling phase.

Our concept of decreasing $\mathrm{E}_{\mathrm{a}}$ along with increasing $\mathrm{E}_{\mathrm{p}}$ during filling, which enables us to explain the LV suction effect during early filling, is indirectly supported by the work of Shoucri [22]. He has indicated that the LV wall stress during the filling phase is made up of two components: (i) a passive increasing component due to LV pressure and (ii) an active decreasing component due to decreasing active fiber stress.

However, the determination of this active fiber stress in his paper is empirical and not based on a well-defined concept and expression for $\mathrm{E}_{\mathrm{a}^{\prime}}$ as provided by us.

Finally, both $\mathrm{E}_{\mathrm{a}}$ and $\mathrm{E}_{\mathrm{p}}$ are invoked to explain the variations of pressure during the ejection and filling phases. From the viewpoint of intrinsic indices of LV assessment, $\mathrm{E}_{\mathrm{p}}$ can represent $\mathrm{LV}$ myocardial stiffness property and resistance to $\mathrm{LV}$ filling. On the other hand, $\mathrm{E}_{\mathrm{a}}$ has been shown to correspond to LV contractility, by means of
Figures 12 \& 13. Therein, we have shown a high degree of correlation between $\mathrm{E}_{\mathrm{a} \text {, max }}$ and $(\mathrm{dP} / \mathrm{dt})_{\max }$ as well as $\mathrm{EF}$.

In future, we can also couple our LV model (of $\mathrm{E}_{\mathrm{p}}$ and $\mathrm{E}_{\mathrm{a}}$ ) with an arterial lumped-parameter model (consisting of total peripheral resistance $\mathrm{R}$, total arterial compliance $\mathrm{C}$, aortic characteristic impedance $\mathrm{Z}_{0}$ and inertial $\mathrm{L}$ ) in order to simulate and explain the mechanisms of chronic hypertensive states [23], in terms of alteration in $\mathrm{E}_{a}$ itself as a measure of LV adaptation to chronic hypertension induced in the circulation system.

\section{Appendix: Derivation of Equation (5)}

Dynamic equilibrium of the LV myocardial element gives (based on figure 14):

$$
\begin{aligned}
& m_{e} d \dot{u}+d P_{e l} A_{e}-d P_{L V} A_{e}=0 \\
& \text { or } m_{s} d \dot{u}+d P_{e l}-d P_{L V}=0
\end{aligned}
$$

where the myocardial element mass, $m_{e}=m_{s} A_{e^{\prime}} m_{s}$ (the myocardial surface-density or mass per unit surface area) $=\rho h, \rho$ is the myocardial density, and $\mathrm{u}$ is the radial displacement, $d P_{e l}$ and $d P_{L V}$ are the incremental elasticrecoil and left ventricular pressures (as depicted in Figure A-1). 
Now since,

$$
m_{s}=\frac{\left.m_{e} \text { (element } \text { mass }\right)}{A_{e}(\text { element surface area })}=\rho h
$$

By assuming $r_{1}=r_{2}=R$

$$
\begin{gathered}
\Delta V=4 \pi R^{2} \Delta u=\dot{V} \Delta t \\
\therefore \dot{V}=4 \pi R^{2} \dot{u} \text {, and } d \dot{V}=4 \pi R^{2} d \dot{u}
\end{gathered}
$$

we can write:

$$
m_{s} d \dot{u}=\frac{(\rho h) d \dot{V}}{4 \pi R^{2}}=\left(\frac{\rho}{4 \pi R^{2}}\right) h d \dot{V}=\rho_{s} h d \dot{V}=M d \dot{V}
$$

where $\rho_{s}$ is the surface density, $M=\rho_{s} h$, and V is the LV volume. Now, referring to Figure A-1,

$$
d\left(P_{L A}-P_{2}\right)=d\left(P_{1}-P_{2}\right)=R_{e} \dot{V}
$$

and

$$
d P_{2}=d P_{L V}-\frac{\rho_{f} v^{2}}{2}
$$

where $R_{e}$ is the resistance to LV filling (through the open mitral-valve), $\rho_{f}$ is the blood density and $v$ is the blood velocity at site 2 .

$$
\therefore d P_{L V}=d P_{L A}-R_{e} \dot{V}+\frac{\rho_{f} v^{2}}{2}
$$

Let us now define incremental elastic recoil pressure (in response to incremental $L V$ pressure $d P_{L V}$ ) as:

$d P_{e l}($ elastic recoil pressure $)=d\left(\frac{V}{C}\right)=d(E V)=E d V+V d E$

Hence, from equations (A-1, A-4, A-7 \& A-8), we have

$$
\begin{aligned}
& M d \dot{V}+d(V / C)=d P_{L V}=d P_{L A}-R_{e} \dot{V}+\rho_{f} v^{2} / 2 \\
& \text { or, } M d \dot{V}+R_{e} \dot{V}+d(V / C)=d P_{L A}+\rho_{f} v^{2} / 2
\end{aligned}
$$

Introducing the term elastance $(=1 / \mathrm{C})$, we can put down

$$
M d \dot{V}+d(V E)=d P_{L A}-R_{e} \dot{V}+\rho_{f} v^{2} / 2=d P_{L V}
$$

\section{Authors' contributions}

Liang Zhong carried out the elastance studies, participated in data acquisition, performed statistical analysis and drafted the manuscript. Dhanjoo N. Ghista conceived of the study, and participated in its design and coordination and helped to draft the manuscript. Eddie Y-K Ng participated in coordination and helped to draft the manuscript.
Soo T Lim participated in its design and coordination. All authors read and approved the final manuscript.

\section{Acknowledgements}

We are grateful to Dr. Terrance S.J. Chua and Technician Mr. Ng Eng Hian from National Heart Centre, Singapore, for his technical assistance in cineangiographic recordings. This study was supported by grants from Strategic Development Scheme, Nanyang Technological University, Singapore.

\section{References}

I. Noordergraaf A, Melbin J: Introducing the pump equation. In The heart and cardiovascular system-scientific foundations Edited by: Haber E, Jennings RB, Katz AM, Morgan HE. New York: Raven Press; 1994:19-35.

2. Palladino JL, Mulier JP, Noordergraaf A: Defining ventricular elastance. Proc 20th Int Conf IEEE Eng Med Biol Soc, Hong Kong 1998:383-386

3. Noordergraaf A: Circulatory system dynamics New York: Academic Press; 1978.

4. Warner HR: The use of an analog computer for analysis of control mechanisms in the circulation. Proc IRE 1959, 47:1913-1916.

5. Defares JG, Osborn JJ, Hara HH: Theoretical synthesis of the cardiovascular system. Acta Physiolo Pharmacol Neerl 1963, 21:189-265

6. Suga H, Sagawa K: Instantaneous pressure volume relationships and their ratio in the excised, supported canine left ventricle. Cir Res 1974, 35: I 17-126.

7. Kennish A, Yellin E, Frater RW: Dynamic stiffness profiles in the left ventricle. J Appl Physiol I 975, 39:665-67I.

8. Suga $\mathrm{H}$ : Time course of left ventricular pressure-volume relationships under various end-diastolic volume. Jap Heart J 1969, 10:509-515.

9. Suga $\mathrm{H}$, Sagawa $\mathrm{K}$, Shoukas AA: Load independence of the instantaneous pressure-volume ratio of the canine left ventricle and effects of epinephrine and heart rate on the ratio. Circ Res 1973, 32:314-322.

10. Suga H, Sagawa K: Instantaneous pressure volume relationships and their ratio in the excised, supported canine left ventricle. Circ Res 1974, 35: I I7-I 26.

II. Sagawa K: The ventricular pressure-volume diagram revisited. Circ Res 1978, 43:677-687.

12. Mehmel HC, Stochins B, Ruffmann K, Olshausen K, Schuler G, Kubler $W$ : The linearity of the end-systolic pressure-volume relationship in man and its sensitivity for assessment of left ventricular function. Circulation 1981, 63(6): $1216-1222$.

13. Little WC, Cheng CP, Mumma M, et al.: Comparison of measures of left ventricular contractile performance derived from pressure-volume loops in conscious dogs. Circulation 1989, 95:2423-2433.

14. Shishido T, Hayashi K, Shigemi K, Sato T, Sugimachi M, Sunagawa K: Single-beat estimation of end-systolic elastance using bilinearly approximated time-varying elastance curve. Circulation 2000, 102:1983-1989.

15. Suga $\mathrm{H}$ : Paul Dudley white international lecture: cardiac performance as viewed through the pressure-volume window. Jpn Heart J 1994, 35:263-280.

16. Sandler H, Dodge HT: The use of single plane angiocardiograms for the calculation of left ventricle volume in man. Am Heart J 1968, 75:325-334.

17. Zhong L, Ghista DN, Ng EYK: Index for cardiac dysfunction of left ventricular filling phase. In Proceedings of the 5th International Conference on Simulations in Biomedicine: 2-4 April 2003 Volume 5. Ljubjana. WIT Press; 2003:209-2I8.

18. Mirsky I: Assessment of passive elastic stiffness of cardiac muscle: mathematical concepts, physiologic and clinical considerations, directions of future research. Prog Cardiovasc Dis 1976, XVIII(4):277-308.

19. Mirsky I, Pasipoularides A: Clinical assessment of diastolic function. Prog Cardiovasc Dis 1990, 32:291-318.

20. Gilbert JC, Glantz SA: Determinants of left ventricular filling and of the diastolic pressure-volume relation. Circ Res 1989 , 64(5):827-852. 
21. Mulier JP: Ventricular pressure as a function of volume and flow. In PhD thesis University of Leuven; 1994.

22. Shoucri RM: Active and passive stresses in the myocardium. Am J Physiol Hear Circ Physiol 2000, 279:H25 I9-H2528.

23. Segers P, Stergiopulos N, Schreuder JJ, Westerhof BE, Westerhof N: Left ventricular wall stress normalization in chronic pressure-overloaded heart: a mathematical model study. Am J Physiol Heart Circ Physiol 2000, 279:HI I20-HI 27.

Publish with Bio Med Central and every scientist can read your work free of charge

"BioMed Central will be the most significant development for disseminating the results of biomedical research in our lifetime. " Sir Paul Nurse, Cancer Research UK

Your research papers will be:

- available free of charge to the entire biomedical community

- peer reviewed and published immediately upon acceptance

- cited in PubMed and archived on PubMed Central

- yours - you keep the copyright

Submit your manuscript here:

http://www.biomedcentral.com/info/publishing_adv.asp
BioMedcentral 